\title{
Heterologous Expression of the Mi-1.2 Gene from Tomato Confers Resistance Against Nematodes but Not Aphids in Eggplant
}

\author{
Fiona L. Goggin, ${ }^{1}$ Lingling Jia, ${ }^{1}$ Gowri Shah, ${ }^{2}$ Stephanie Hebert, ${ }^{1}$ Valerie M. Williamson, ${ }^{3}$ and \\ Diane E. UlIman ${ }^{4}$ \\ ${ }^{1}$ Department of Entomology, University of Arkansas, 320 Agriculture Building, Fayetteville, AR 72701, U.S.A.; ${ }^{2}$ DNA Plant \\ Technologies, 6701 San Pablo Ave., Oakland, CA, 94608, U.S.A.; ${ }^{3}$ Department of Nematology, University of California, \\ 1 Shields Ave., Davis, CA 95616, U.S.A.; ${ }^{4}$ Department of Entomology, University of California, 1 Shields Ave., Davis, \\ CA 95616, U.S.A.
}

Submitted 5 August 2005. Accepted 4 January 2006.

\begin{abstract}
The Mi-1.2 gene in tomato (Solanum lycopersicum) is a member of the nucleotide-binding leucine-rich repeat (NBLRR) class of plant resistance genes, and confers resistance against root-knot nematodes (Meloidogyne spp.), the potato aphid (Macrosiphum euphorbiae), and the sweet potato whitefly (Bemisia tabaci). Mi-1.2 mediates a rapid local defensive response at the site of infection, although the signaling and defensive pathways required for resistance are largely unknown. In this study, eggplant (S. melongena) was transformed with $M i-1.2$ to determine whether this gene can function in a genetic background other than tomato. Eggplants that carried $\mathrm{Mi}-1.2$ displayed resistance to the root-knot nematode Meloidogyne javanica but were fully susceptible to the potato aphid, whereas a susceptible tomato line transformed with the same transgene was resistant to nematodes and aphids. This study shows that $\mathrm{Mi}$ 1.2 can confer nematode resistance in another Solanaceous species. It also indicates that the requirements for $\mathrm{Mi}$-mediated aphid and nematode resistance differ. Potentially, aphid resistance requires additional genes that are not conserved between tomato and eggplant.
\end{abstract}

Additional keywords: insect resistance, Lycopersicon esculentum, restricted taxonomic functionality.

The Mi-1.2 gene in tomato (Solanum lycopersicum syn. Lycopersicon esculentum) confers race-specific resistance against root-knot nematodes (Meloidogyne spp.), potato aphids (Macrosiphum euphorbiae), and sweet potato whiteflies (Bemisia tabaci) (Milligan et al. 1998; Nombela et al. 2003; Rossi et al. 1998). This locus was introgressed into cultivated tomato over 60 years ago through hybridization with a wild tomato species, S. peruvianum (syn. L. peruvianum) (Smith 1944). More recently, Mi-1.2 was cloned through a map-based approach and categorized in a class of plant resistance genes characterized by coiled-coil (CC), nucleotide-binding (NB), and leucine-rich repeat (LRR) motifs (Milligan et al. 1998). Many other CC-NB-LRR genes confer race-specific resistance to plant-pathogenic bacteria, fungi, viruses, and nematodes

Corresponding author: Fiona L. Goggin; Telephone: (479) 575-6751; Fax: (479) 575-2452; E-mail: fgoggin@uark.edu

Current address of G. Shah: Pioneer Hi-Bred International Inc., Verdia Campus, 700-A Bay Road, Redwood City, CA 94603 U.S.A.
(Dangl and Jones 2001). Mi-1.2 is the first insect resistance gene to be identified in this class, and the only known racespecific resistance gene ( $R$ gene) to confer resistance against such phylogenetically and ecologically divergent pest species.

Root-knot nematodes (phylum Nematoda) are soilborne endoparasitic roundworms that penetrate roots intercellularly and that induce the formation of specialized feeding sites called giant cells in the developing vascular tissue of the root tips. After an infective juvenile nematode has established a feeding site, it matures into a sedentary adult and completes its life cycle within the root (Williamson and Gleason 2003). In contrast, potato aphids and whiteflies (phylum Arthropoda) are highly mobile foliar pests that ingest phloem sap through piercing-sucking mouthparts. All three of these organisms are significant agricultural pests with broad host ranges. Root-knot nematodes infect thousands of plant species and are estimated to cause as much as $\$ 100$ billion per year in worldwide crop losses (Barker and Koenning 1998; Sasser and Freckman 1987). Symptoms of nematode infestation include root galls, stunted growth, and increased susceptibility to drought stress and pathogen infection. The potato aphid can colonize over 200 crops in more than 20 plant families (Blackman and Eastop 1984), and the sweet potato whitefly infests at least 400 species in 74 plant families (Brown et al. 1995). These insects cause significant direct damage such as leaf curling and chlorosis, and also are important vectors of phytopathogenic viruses (Brown et al. 1995; Walgenbach 1997). Aphids and whiteflies are particularly difficult to control because of the high occurrence of pesticide resistance among these insects (Nauen and Denholm 2005).

Because root-knot nematodes, aphids, and whiteflies are major pests of a broad range of crops, transfer of $M i$-mediated resistance to other plant species would be highly desirable. Several other $R$ genes have been transferred successfully among Solanaceaous species through plant transformation (Fig. 1). The $N$ gene from tobacco (Nicotiana tabacum), the $B s 2$ gene from pepper (Capsicum chacoense), and the Rpiblb1 gene from a wild potato species (S. bulbocastanum) all reduce disease in transgenic tomato plants (Tai et al. 1999; van der Vossen et al. 2003; Whitham et al. 1996). Likewise, the Pto gene from tomato can confer race-specific bacterial resistance in $N$. benthamiana (Rommens et al. 1995). $R$ genes, however, do not always function in heterologous genetic backgrounds. For example, when RPW8.1 and RPW8.2 were transferred from Arabidopsis thaliana (Brassicaceae) to Solanaceous spe- 
cies, they conferred powdery mildew resistance in tobacco but not in tomato (Xiao et al. 2003). Likewise, the potato cyst nematode resistance gene Hero, which is derived from the wild tomato species $S$. pimpinellifolium and bears strong similarity to $M i-1.2$, conferred resistance when transferred to susceptible cultivated tomato but failed to confer nematode resistance in potato (Sobczak et al. 2005). Taxonomic relationships among plants influence the likelihood of successful transfer of resistance, and it is rare for a single $R$ gene to function in more than one plant family (Frost et al. 2004; Tai et al. 1999; Xiao et al. 2003). This phenomenon is referred to as restricted taxonomic functionality (Tai et al. 1999). The failure of an $R$ gene to confer resistance in a heterologous background may be due to the absence of other receptors, regulatory elements, or signaling or defensive genes required for the $R$-gene-mediated defense response.

The primary goal of this project was to determine whether Mi-1.2 could confer nematode and insect resistance in a genetic background other than tomato. To this end, Mi-1.2 was introduced through plant transformation into eggplant ( $S$. melongena), and nematode and aphid performance were assayed on the transgenic plants. Eggplant was chosen for study in part because of its agricultural importance, and because root-knot nematodes are a major yield constraint for this plant (Di Vito et al. 1986). According to the Food and Agriculture Organization of the United Nations, nearly two million hectares of eggplant were harvested worldwide in 2004, making it the third most commonly grown vegetable crop in the family Solanaceae (FAOSTAT 2005). Furthermore, among crops in this plant family, eggplant is second only to tomato in yield per hectare (FAOSTAT 2005). Eggplant also was chosen for study on the basis of its taxonomic relationship to tomato (Fig. 1), as well as its amenability to Agrobacterium-mediated transformation. Based on chloroplast DNA restriction fragment analysis, tomato and eggplant are both classified in the genus Solanum, the largest and most diverse genus in the family Solanaceae (Knapp et al. 2004; Spooner et al. 1993). Eggplant, however, is endemic to the Old World, whereas tomato is a New World species (Olmstead and Palmer 1997), and genetic linkage maps indicate that eggplant and tomato are distinguished by 28 chromosomal rearrangements (Doganlar et al. 2002). Therefore, eggplant represents a suitable model in which to test the ability of $M i-1.2$ to function in a related but divergent genetic background.

\section{RESULTS}

\section{Nematode performance on eggplant.}

Two independent assays were performed to assess reproduction of the root-knot nematode Meloidogyne javanica on four eggplant lines transformed with $M i-1.2$. Reproduction was ex-

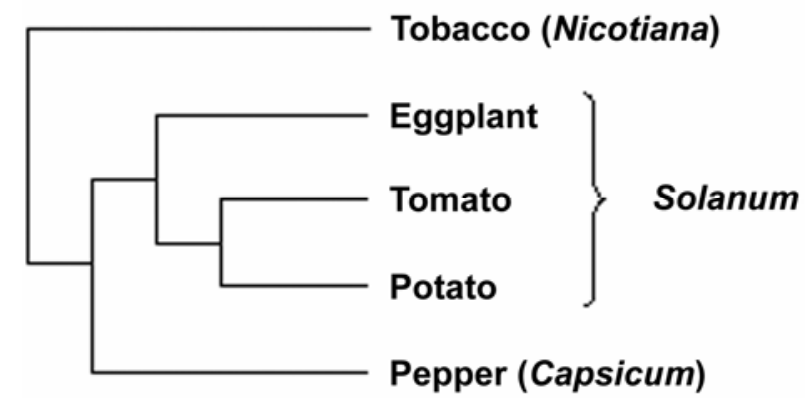

Fig. 1. Cladogram of the major crops in the family Solanaceae. Resistance genes from tobacco, potato, and pepper have been successfully transferred to tomato. This cladogram was based on phylogenies presented by Olmstead and Palmer (1997) and Knapp and associates (2004). pressed in terms of egg masses per gram of root tissue because total egg mass numbers often vary with root size. Egg mass numbers were significantly lower on the transgenic lines 006 and 017 than on the untransformed control, cv. HP83 $(P=$ 0.001 ) (Table 1 , trial 1). Nematode reproduction also was significantly lower on two additional independent events, 016 and 003, than on HP83 $(P=0.001)$ (Table 1, trial 2). Assessment of resistance in line 003 was repeated two additional times with similar results (data not shown).

\section{Aphid performance on eggplant and tomato.}

Three independent assays were performed to assess shortterm aphid population growth on eggplant lines 006, 017, and 003 and 016 . We recorded the number of adult aphids that survived in each cage, as well as the number of offspring they produced, and the average numbers of total aphids per cage per plant are reported in Figure 2. Total aphid numbers were higher on 006 than on HP83 (Fig. 2A), but were not significantly different at $\alpha=0.05(P=0.085)$. Neither adult survival $(P=0.158)$ nor offspring production $(P=0.094)$ differed significantly between these lines. Numbers of surviving adults $(P$ $=0.342)$, offspring $(P=0.219)$, and total aphids $(P=0.214)$ also did not differ between HP83 and 017 (Fig. 2B). Likewise, aphid survival $(P=0.664)$, reproduction $(P=0.702)$, and total numbers $(P=0.700)$ did not differ among genotypes when 003, 016, and HP83 were compared (Fig. 2C). Evaluation of aphid performance on eggplant lines 006 and 017 was repeated once with similar results (data not shown).

In contrast, adult survival $(P=0.043)$, offspring numbers $(P$ $<0.001)$, and total aphid populations $(P<0.001)$ were significantly reduced on the transgenic tomato line 143-25 when compared with aphid performance on the isogenic susceptible cv. Moneymaker (Fig. 3). This experiment was repeated once with similar results (data not shown). Line 143-25 carries the same $M i-1.2$ construct as the transgenic eggplant lines. This data demonstrates that $M i-1.2$ is effective against the aphid isolate used for this study, and confirms prior findings with other transgenic lines and aphid isolates that $M i-1.2$ confers aphid resistance (Goggin et al. 2004a; Rossi et al. 1998). The transgenic tomato line used in this experiment also was previously shown to be resistant to the $M$. javanica isolate used in this study (Milligan et al. 1998).

\section{Detection of $\mathrm{Mi}$-1.2 transcripts in transgenic eggplant.}

In reverse-transcription polymerase chain reaction (RTPCR) assays, $M i$-specific primers amplified a single band of $915 \mathrm{bp}$ in both roots and leaves of all four independently transformed eggplant lines, and did not generate any PCR products in the untransformed control plants (Fig. 4). This indicates that the $M i-1.2$ transgene was transcribed in both roots and leaves

Table 1. Nematode reproduction on eggplant lines with and without $M i-1.2$

\begin{tabular}{lcc}
\hline Genotype & Replicates & Egg masses/g of root mass $\pm \mathbf{S D}^{\mathbf{z}}$ \\
\hline Trial 1 & & $29 \pm 39 \mathrm{~A}$ \\
HP83 $(M i-)$ & 6 & $2 \pm 2 \mathrm{~B}$ \\
017 $(M i+)$ & 6 & $2 \pm 1 \mathrm{~B}$ \\
006 $(M i+)$ & 9 & $21 \pm 23 \mathrm{~A}$ \\
Trial 2 & & $1 \pm 1 \mathrm{~B}$ \\
HP83 $(M i-)$ & 6 & $3 \pm 3 \mathrm{~B}$ \\
016 $(M i+)$ & 5 & 6 \\
003 $(M i+)$ & 6 & \\
\hline
\end{tabular}

${ }^{\mathrm{z}}$ Nematode reproduction was assessed on plants 7 weeks after inoculation with 4,000 M. javanica infective juveniles. Within each trial, values labeled with different letters are significantly different according to Tukey's highly significant difference test. Statistics were performed on $\log$ transformations of the data; $\mathrm{SD}=$ standard deviation. 
of the transgenic plants, and that our primers did not amplify $M i$ orthologs in eggplant. Ubiquitin transcripts were detected in all samples, confirming adequate cDNA synthesis. PCR also was performed using ubiquitin primers on RNA samples prior to reverse transcription (RT-minus controls), and the lack of amplification in these samples confirmed the absence of contaminating genomic DNA (Fig. 4).

\section{DISCUSSION}

This study demonstrates that the $M i-1.2$ resistance gene from tomato retains partial function when introduced into another Solanaceous species. In transgenic eggplant, $\mathrm{Mi}-1.2 \mathrm{con}$ fers resistance against nematodes but not aphids, although it is effective against both pests in tomato. Potentially, this could be due to deficiencies in the translation or processing of the $\mathrm{Mi}$ 1.2 protein in eggplant leaves. Alternatively, these data may indicate that the requirements for $M i$-mediated aphid and nematode resistance differ, and that some factor necessary for aphid
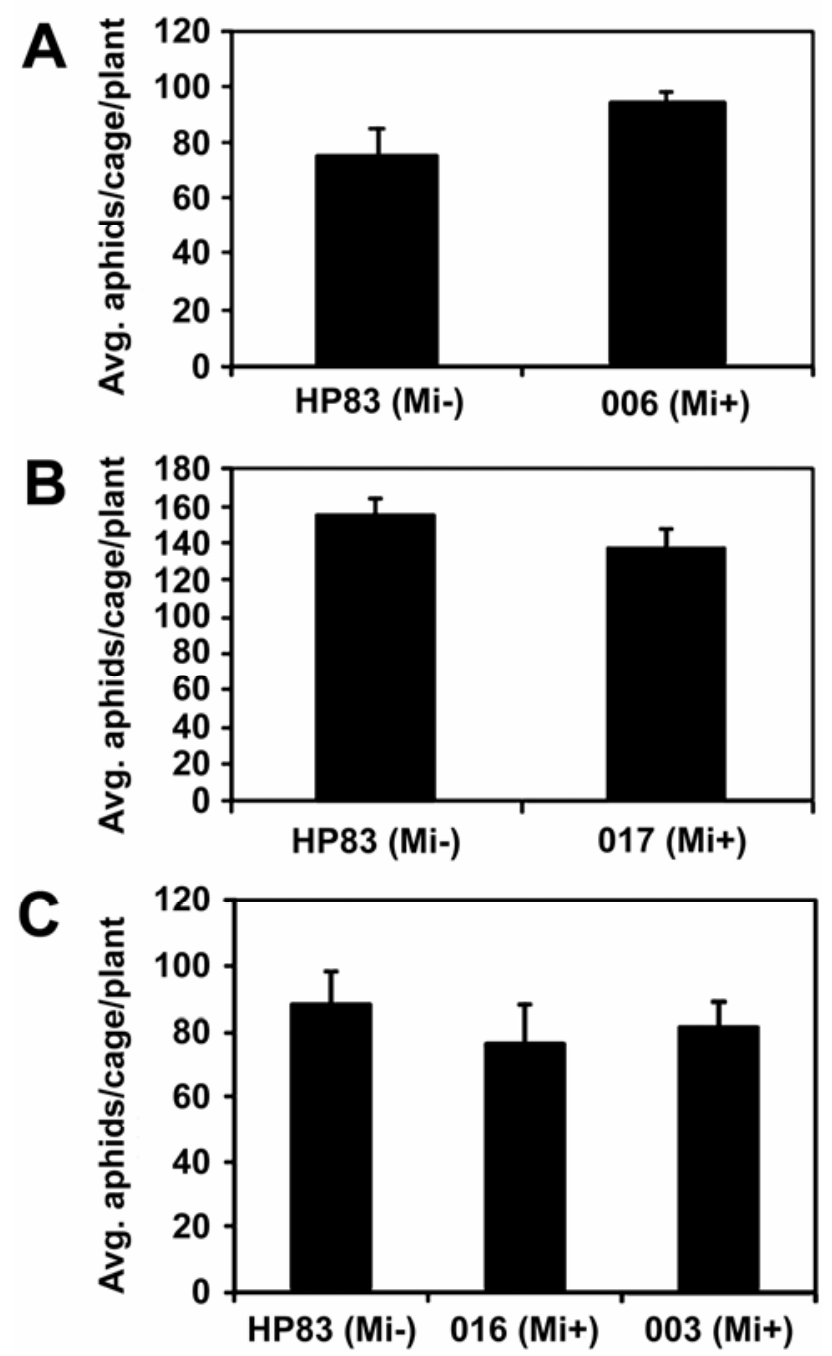

Fig. 2. Short-term aphid population growth on eggplant lines with and without $M i-1.2$. Aphids were confined to the foliage in clip cages (13 aphids/cage, two cages/plant) to assess their performance on susceptible eggplant cv. HP83 and four independently transformed eggplant lines, A, 006, B, 017, and C, 016 and 003. Surviving aphids and offspring were counted 5 days after inoculation, aphid numbers were averaged between the two cages per plant, and these averages were analyzed by one-way analysis of variance. Within each assay, there were no significant differences in aphid numbers among plant genotypes. Error bars represent the standard error of the means for each treatment. resistance is not conserved between tomato and eggplant. Another important difference between $M i$-mediated nematode and aphid resistance is that aphid resistance is developmentally regulated in tomato, whereas nematode resistance is constitutively expressed (Goggin et al. 2004b). Furthermore, nematode resistance is associated with a hypersensitive response at the attempted feeding site (Dropkin 1969; Riggs and Winstead 1959), whereas no cell death has been detected at aphid feeding sites on resistant plants (Martinez de Ilarduya et al. 2003). Taken together, these data suggest that the signaling or defensive pathways underlying $M i$-mediated aphid and nematode resistance may be divergent.

By analogy to other known $R$ genes, it has been hypothesized that $M i-1.2$ mediates gene-for-gene interactions with nematodes and insects, in which recognition of as-yetunknown elicitors from the pests triggers rapid, local defense responses (Rossi et al. 1998). Mi-mediated aphid and nematode resistance could require different recognition factors in the plant, or might diverge downstream of Mi-1.2. Experiments in Arabidopsis suggest that a single $R$ gene can activate more than one parallel signaling pathway; for example, in the case of downy mildew resistance in Arabidopsis, the RPP7 R gene activates both the RARl and NDRl signaling cascades, and $R P P 4$ requires different signaling components in true leaves versus cotyledons (Tornero et al. 2002; van der Biezen et al. 2002). At present, the recognition and signaling events required for $\mathrm{Mi}$-mediated nematode and insect resistance are not well understood. Both forms of resistance are reported to require the signaling compound salicylic acid and the chaperonin Hsp90 (Branch et al. 2004; Kaloshian 2004). To date, only one other locus required for $M i$-mediated resistance has been identified (Martinez de Ilarduya et al. 2001). Rmel is necessary for both nematode and insect resistance, and appears to be involved in an early stage of the resistance response (Martinez de Ilarduya et al. 2004). Further work is needed to clone this gene, and also to identify other nodes of the resistance pathway.

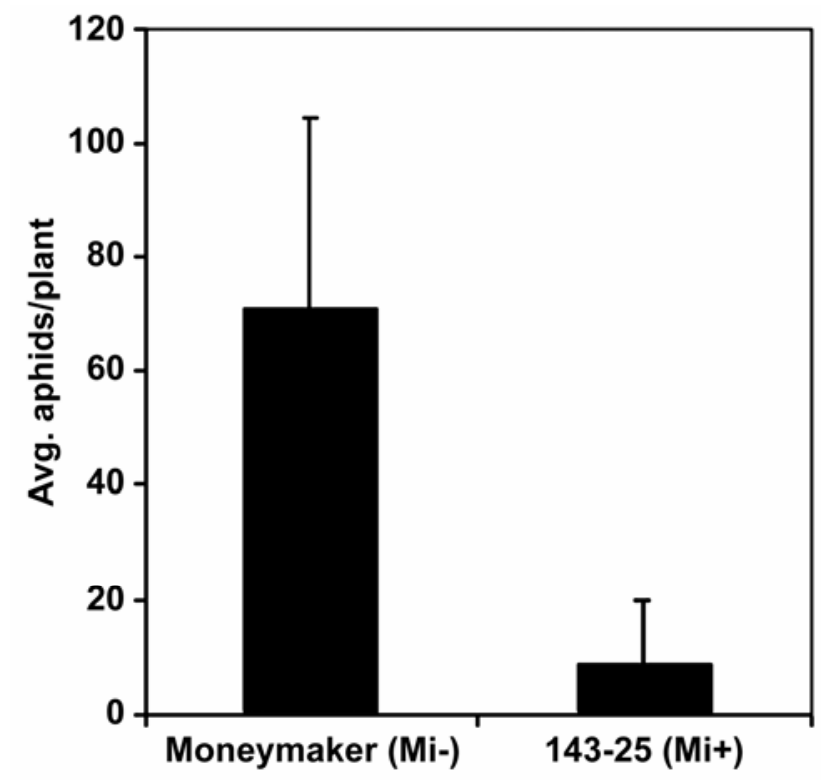

Fig. 3. Short-term aphid population growth on tomato lines with and without $M i-1.2$. Aphids were confined to individual leaflets using sleeve cages (15 aphids/cage, one cage/plant), and aphid numbers were assessed 6 days after inoculation. Total aphid numbers per plant (adults and offspring) were significantly lower on plants that carry $M i-1.2$ according to one-way analysis of variance $(P<0.001)$. Error bars represent the standard deviation of each treatment. 
Another direction for future studies would be to test the function of Mi-1.2 in other species within the genus Solanum. Potato ( $S$. tubersosum) would be of particular interest because, compared with eggplant, it is estimated to be three- to sixfold more closely related to tomato (Doganlar et al. 2002). Based on what is known about other $R$ genes, it is unlikely that $M i-1.2$ would confer resistance in other plant families, and we have confirmed that it lacks activity in Arabidopsis (Brassicaceae) and lettuce (Asteraceae) (V. M. Williamson and G. Shah, unpublished data). Mi-1.2 also cannot impart resistance to tobacco (N. tabacum cv. Xanthi) (V. M. Williamson, unpublished data), indicating that Mi-1.2 may not function across genera. In tobacco, the downstream defense pathways involved in $M i$-mediated resistance appear to be intact, because transient expression of constitutively active mutant forms of the Mi-1.2 LRR domain cause a hypersensitive response in $N$. benthamiana (Hwang et al. 2000; Hwang and Williamson 2003). Therefore, the lack of Mi-mediated resistance in tobacco may be due to the absence of recognition factors or other elements required in the early stages of the induced response. In the future, the elucidation of the recognition events and signaling pathways required for $M i$-mediated resistance should facilitate the transfer of resistance to new species, and shed light on the diversification of $R$-gene-mediated responses during plant evolution.

\section{MATERIALS AND METHODS}

Plant materials.

The susceptible eggplant cv. HP83 and the susceptible tomato cv. Moneymaker were transformed with construct pSM137 in Agrobacterium tumefaciens (strain LBA4404). The pSM137 construct contains a $14.7-\mathrm{kb}$ insert of tomato genomic DNA in
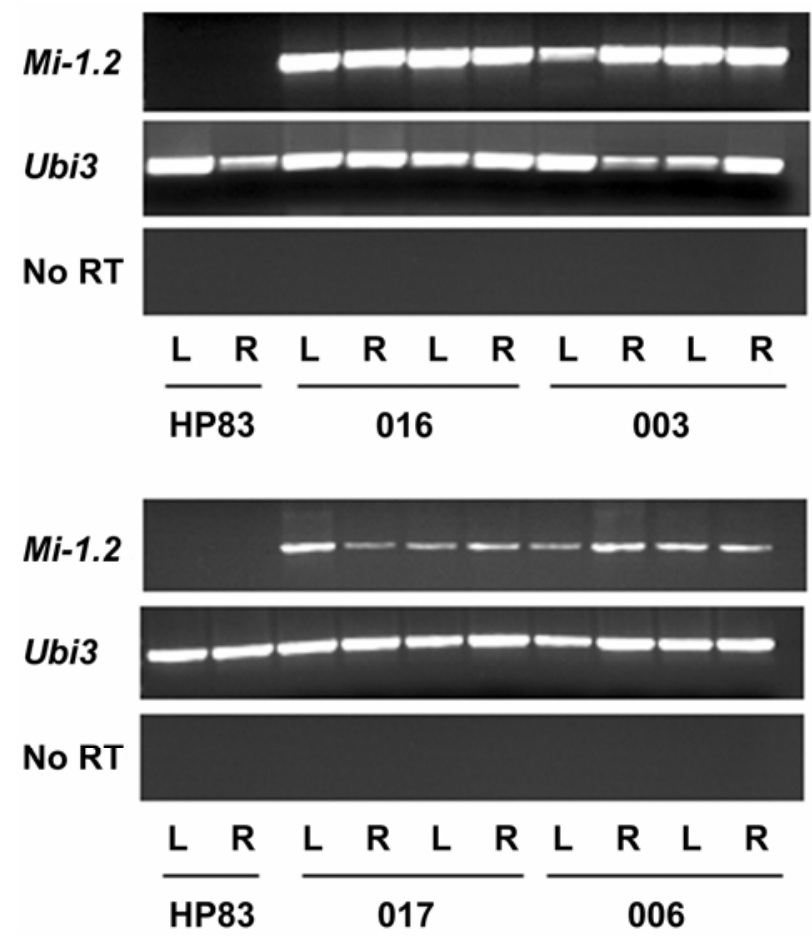

Fig. 4. Detection of $M i-1.2$ transcripts in transgenic eggplant lines. Total RNA was extracted from roots (R) and leaves (L) of four independent transgenic lines $(017,006,016$, and 003; two plants each), and the untransformed control HP83 (one sample pooled from two plants). Reversetranscription polymerase chain reaction (RT-PCR) was performed with primers specific to $M i-1.2$ and ubiquitin (Ubi3). A control reaction lacking reverse transcriptase was performed for each RNA sample, and used as a template for a PCR with ubiquitin primers (no RT). binary vector pCGN1557, including the entire $M i-1.2$ coding region, $4.62 \mathrm{~kb}$ of sequence $5^{\prime}$ of the putative transcription start site, and $4.77 \mathrm{~kb}$ of $3^{\prime}$ of the polyadenylation site (Milligan et al. 1998). Plant transformation was performed according to the methods of Fillatti and associates (1987). Four independent transgenic eggplant lines $(003,006,016$, and $017)$ and one transgenic tomato line (143-25) were used for this study. The original transformants were designated the T0 generation, and all assays were performed using the T2 generation. Plants that were positive for the transgene were identified from segregating populations by PCR screening as described by Goggin and associates (2004a), using primers specific to the kanamycin resistance gene NPTII.

Plants for use in nematode assays were grown in 0.95-liter Styrofoam cups of autoclaved sand (Quikrete, Atlanta), and plants for use in aphid assays were grown in 3.8-liter pots of LC1 Sunshine potting mix (Sungro Horticulture, Bellevue, WA, U.S.A.). All plants were grown under stable greenhouse conditions (approximately 24 to $27^{\circ} \mathrm{C}$; photoperiod, $16 \mathrm{~h}$ of light and $8 \mathrm{~h}$ of darkness), and watered daily with dilute nutrient solution as described previously (Cooper et al. 2004).

\section{Nematode bioassays.}

$M$. javanica strain VW4 was maintained on susceptible tomato plants (cv. Moneymaker) in hydroponic culture in aerated Miller's Supreme 16-4-16 fertilizer solution (Miller Chemical \& Fertilizer Corporation, Hanover, PA, U.S.A.). Infective second-stage juveniles for use in bioassays were collected from these hydroponic cultures by vacuum filtration (Lambert et al. 1995). Nematode performance was assayed on four independent transgenic eggplant lines, and untransformed eggplants (cv. HP83) were included as a susceptible control. Six-week-old eggplants were inoculated with approximately 4,000 infective juveniles per plant, which were injected into the sand surrounding the root systems (5 to 6 replicate plants per genotype). Nematode establishment and reproduction was compared by measuring the number of egg masses produced per plant 7 weeks after inoculation. Root systems were washed of all sand and immersed for $10 \mathrm{~min}$ in erioglaucine solution $(0.1 \mathrm{~g} / \mathrm{liter})$ (Sigma-Aldrich, St. Louis, U.S.A.) to stain the egg masses, and the total numbers of egg masses per plant were counted (Yaghoobi et al. 1995). Each root system then was dried at $45^{\circ} \mathrm{C}$ in an incubator in order to measure dry root weights. Nematode performance was evaluated using the number of egg masses/dry root weight/plant. Unequal variances were stabilized by $\log$ transformation using the equation $\log (Y+1)$, where $Y=$ egg masses/dry root weight/plant (Gomez and Gomez 1984). Analysis of variance (ANOVA) was conducted using the general linear model procedure with JMP statistical software (version 5.01; SAS Inc., Cary, NC, U.S.A.).

\section{Aphid bioassays.}

Macrosiphum euphorbiae isolate WU11 was reared on susceptible tomato seedlings (cv. UC82) in a growth chamber $\left(20^{\circ} \mathrm{C}\right.$; photoperiod, $16 \mathrm{~h}$ of light and $8 \mathrm{~h}$ of darkness). Aphid performance was compared on four transgenic eggplant lines and the untransformed cv. HP83. Eggplants were assayed for aphid resistance at the onset of flowering, approximately 10 weeks after planting. Aphids were confined to plastic clip cages (approximately $3 \mathrm{~cm}$ high and $3 \mathrm{~cm}$ in diameter) on the abaxial surfaces of fully expanded leaves (13 aphids/cage, two cages/plant), and leaf positions were standardized from plant to plant. There were 6 to 11 replicate plants per treatment for each bioassay (11 replicates for assay 1, Fig. 2A; 10 replicates for assay 2, Fig. 2B; and 6 replicates per treatment for assay 3, Fig. 2C). The numbers of surviving adults and their progeny per cage were counted 5 days after inoculation, aphid numbers 
were averaged between the two cages per plant, and ANOVA was performed on these averages using JMP version 5.01. Because different aphid isolates can vary in their response to $\mathrm{Mi}$ 1.2 (Goggin et al. 2001), aphid performance also was assessed on the transgenic tomato line 143-25 and the untransformed cv. Moneymaker to confirm that aphid isolate WU11 is avirulent. Tomato plants were inoculated with aphids at the onset of flowering ( 6 weeks after planting), and aphids were confined to the terminal leaflet of the eighth leaf from the cotyledon using nylon sleeve cages (15 aphids/cage, one cage/plant, nine plants/treatment). The surface areas of individual leaflets varied, but were between two to three times the sizes of the clip cages used in the eggplant assay. Six days after inoculation, total aphid numbers were counted and analyzed by one-way ANOVA. All bioassays were performed in a Conviron growth chamber under optimal conditions for aphid growth $\left(20^{\circ} \mathrm{C}\right.$; photoperiod, $16 \mathrm{~h}$ of light and $8 \mathrm{~h}$ of darkness).

\section{Molecular analysis.}

In the absence of anti-Mi 1.2 antibodies or other protein tools to measure $M i$ expression, RT-PCR was chosen as a measure to detect $M i-1.2$ gene expression in the roots and foliage of eggplant lines 003, 006, 016, and 017 (two replicate plants per genotype) and HP83 (one sample pooled from two plants). RNA was extracted from roots and foliage using the protocol of Dunsmuir and associates (1987). cDNA was synthesized from total RNA (1 $\mu \mathrm{g} / \mathrm{sample})$ using an ImPromII Reverse Transcriptase kit and oligo-DT primers (Promega Corp., Madison, WI, U.S.A.), and Mi-1.2 transcripts were PCR amplified using the gene-specific primers C2D1 (5'-CTAGAA AGTCTGTTTGTGTCTAACAAAGG-3') and C2S4 (5'-CTAA GAGGAATCTCATCACAGG-3') (Milligan et al. 1998). In separate PCR amplifications, expression of the housekeeping gene ubiquitin III (Ubi3) was measured using the following primers: Ubi3 forward 5'-GAAAACCCTAACGGGGAAG-3' and reverse $5^{\prime}$-GCCTCCAGCCTTGTTGTAAA-3'. PCR with ubiquitin primers also was performed on total RNA from each sample $(1 \mu \mathrm{g})$ to confirm that the samples did not contain genomic DNA ("no RT" controls). PCR was performed using an MJ Research PTC-200 thermal cycler (MJ Research, San Francisco). Conditions for PCR reactions with $\mathrm{Mi}$-specific primers were $2 \mathrm{~min}$ at $94^{\circ} \mathrm{C} ; 30$ cycles of $94^{\circ} \mathrm{C}$ for $1 \mathrm{~min}, 60^{\circ} \mathrm{C}$ for $1 \mathrm{~min}$, and $72^{\circ} \mathrm{C}$ for $2 \mathrm{~min}$; followed by $5 \mathrm{~min}$ at $72^{\circ} \mathrm{C}$. Similar PCR conditions were used for the Ubi3 primers, with the exception that the annealing temperature was $55^{\circ} \mathrm{C}$. PCR products were visualized by gel electrophoresis using a $1 \%$ agarose gel.

\section{ACKNOWLEDGMENTS}

This work was funded by the Arkansas Agricultural Experiment Station Research Initiative program. We would like to thank F. Chen, S. Kelley, and A. Cameron for their assistance with aphid colonies; R. McNew for advice on statistical analysis; and J. Guerber for his help with greenhouse maintenance.

\section{LITERATURE CITED}

Barker, K. R., and Koenning, S. R. 1998. Developing sustainable systems for nematode management. Annu. Rev. Phytopathol. 36:165-205.

Blackman, R., and Eastop, V. 1984. Aphids on the World's Crops: An Identification and Information Guide. John Wiley and Sons, Chichester, England.

Branch, C., Hwang, C. F., Navarre, D. A., and Williamson, V. M. 2004. Salicylic acid is part of the $M i$-1-mediated defense response to rootknot nematode in tomato. Mol. Plant-Microbe Interact. 17:351-356.

Brown, J., Frohlich, D., and Rossell, R. 1995. The sweet-potato or silverleaf whiteflies-biotypes of Bemisia tabaci or a species complex. Annu. Rev. Entomol. 40:511-534.
Cooper, W., Jia, L., and Goggin, F. L. 2004. Acquired and R-gene-mediated resistance against the potato aphid in tomato. J. Chem. Ecol. 30:2527-2542.

Dangl, J., and Jones, J. 2001. Plant pathogens and integrated defense responses to infection. Nature 411:826-833.

Di Vito, M., Greco, N., and Garella, A. 1986. Effect of Meloidogyne incognita and importance of the inoculum on the yield of eggplant. J. Nematol. 18:487-490.

Doganlar, S., Frary, A., Daunay, M., Lester, R., and Tanksley, S. 2002. A comparative genetic linkage map of eggplant (Solanum melongena) and its implications for genome evolution in the Solanaceae. Genetics 161:1697-1711.

Dropkin, V. H. 1969. The necrotic reaction of tomatoes and other hosts resistant to Meloidogyne: Reversal by temperature. Phytopathology 59:1632-1637.

Dunsmuir, P., Bond, D., Lee, K., Gidoni, D., and Townsend, J. 1987. The expression of introduced genes in regenerated plants. Pages 45-59 in: Plant Molecular Biology Manual. S Gelvin and R Schilperoort, eds. Plenum Press, New York, U.S.A.

FAOSTAT. 2005. Food and Agriculture Organization of the United Nations. Agricultural production indices, 2004. Last updated in January 2005. Published online.

Fillatti, J., Kiser, J., Rose, R., and Comai, L. 1987. Efficient transfer of a glyphosphate tolerance gene into tomato using a binary Agrobacterium tumefaciens vector. Biotechnology 5:726-730.

Frost, D., Way, H., Howles, P., Luck, J., Manners, J., Hardham, A., Finnegan, J., and Ellis, J. 2004. Tobacco transgenic for the flax rust resistance gene $L$ expresses allele-specific activation of defense responses. Mol. Plant-Microbe Interact. 17:224-232.

Goggin, F. L., Williamson, V. M., and Ullman, D. E. 2001. Variability in the response of Macrosiphum euphorbiae and Myzus persicae (Hemiptera: Aphididae) to the tomato resistance gene $\mathrm{Mi}$. Environ. Entomol. 30:101-106.

Goggin, F. L., Shah, G., Williamson, V. M., and Ullman, D. E. 2004a. Developmental regulation of $\mathrm{Mi}$-mediated aphid resistance is independent of Mi-1.2 transcript levels. Mol. Plant-Microbe Interact. 17:532-536.

Goggin, F. L., Shah, G., Williamson, V. M., and Ullman, D. E. 2004b. Instability of $\mathrm{Mi}$-mediated nematode resistance in transgenic tomato plants. Mol. Breed. 13:357-364.

Gomez, K. A., and Gomez, A. A. 1984. Statistical Procedures for Agricultural Research. Wiley-Interscience, New York, U.S.A.

Hwang, C. F., Bhakta, A. V., Truesdell, G. M., Pudlo, W. M., and Williamson, V. M. 2000. Evidence for a role of the $\mathrm{N}$ terminus and leucine-rich repeat region of the $M i$ gene product in regulation of localized cell death. Plant Cell 12:1319-1329.

Hwang, C. F., and Williamson, V. M. 2003. Leucine-rich repeat-mediated intramolecular interactions in nematode recognition and cell death signaling by the tomato resistance protein $\mathrm{Mi}$. Plant J. 34:585-593.

Kaloshian, I. 2004. Gene-for-gene disease resistance: Bridging insect pest and pathogen defense. J. Chem. Ecol. 30:2419-2437.

Knapp, S., Bohs, L., Nee, M., and Spooner, D. M. 2004. Solanaceae-A model for linking genomics with biodiversity. Comput. Funct. Genom. 5:285-291.

Lambert, K., Tedford, E., Caswell, E., and Williamson, V. M. 1995. A system for continuous production of root-knot nematode juveniles in hydroponic culture. Phytopathology 82:512-515.

Martinez de Ilarduya, O. M., Moore, A. E., and Kaloshian, I. 2001. The tomato Rme 1 locus is required for $M i-1$-mediated resistance to root-knot nematodes and the potato aphid. Plant J. 27:417-425.

Martinez de Ilarduya, O. M., Xie, Q. G., and Kaloshian, I. 2003. Aphidinduced defense responses in $\mathrm{Mi}$-1-mediated compatible and incompatible tomato interactions. Mol. Plant-Microbe Interact. 16:699-708.

Martinez de Ilarduya, O. M., Nombela, G., Hwang, C. F., Williamson, V. M., Muniz, M., and Kaloshian, I. 2004. Rme1 is necessary for Mi-1-mediated resistance and acts early in the resistance pathway. Mol. PlantMicrobe Interact. 17:55-61.

Milligan, S. B., Bodeau, J., Yaghoobi, J., Kaloshian, I., Zabel, P., and Williamson, V. M. 1998. The root knot-nematode resistance gene $M i$ from tomato is a member of the leucine zipper, nucleotide binding, leucine-rich repeat family of plant genes. Plant Cell 10:1307-1319.

Nauen, R., and Denholm, I. 2005. Resistance of insect pests to neonicotinoid insecticides: Current status and future prospects. Arch. Insect Biochem. Physiol. 58:200-215.

Nombela, G., Williamson, V. M., and Muniz, M. 2003. The root-knot nematode resistance gene $\mathrm{Mi}-1.2$ of tomato is responsible for resistance against the whitefly Bemisia tabaci. Mol. Plant-Microbe Interact. 16:645-649.

Olmstead, R., and Palmer, J. 1997. Implications for the phylogeny, classification, and biogeography of Solanum from cpDNA restriction site variation. Syst. Bot. 22:19-29. 
Riggs, R. D., and Winstead, N. N. 1959. Studies on resistance in tomato to root-knot nematodes and on the occurrence of pathogenic biotypes. Phytopathology 49:716-724.

Rommens, C., Salmeron, J., Oldroyd, G., and Staskawicz, B. 1995. Intergeneric transfer and functional expression of the tomato disease resistance gene Pto. Plant Cell 7:1537-1544.

Rossi, M., Goggin, F. L., Milligan, S. B., Kaloshian, I., Ullman, D. E., and Williamson, V. M. 1998. The nematode resistance gene $\mathrm{Mi}$ of tomato confers resistance against the potato aphid. Proc. Natl. Acad. Sci. U.S.A. 95:9750-9754.

Sasser, J. N. and Freckman, D. W. 1987. A world perspective on nematology: The role of the society. Pages 7-14 in: Vistas on Nematology. J. A. Veech and D. W. Dickson, eds. Society of Nematologists, Hyattsville, MD, U.S.A.

Smith, P. 1944. Embryo culture of a tomato species hybrid. Proc. Am. Soc. Hortic. Sci. 44:413-416.

Sobczak, M., Avrova, A., Jupowicz, J., Phillips, M. S., Ernst, K., and Kumar, A. 2005. Characterization of susceptibility and resistance responses to potato cyst nematode (Globodera spp.) infection of tomato lines in the absence and presence of the broad-spectrum nematode resistance Hero gene. Mol. Plant-Microbe Interact. 18:158-68.

Spooner, D., Anderson, G., and Jansen, R. 1993. Chloroplast DNA evidence for the interrelationships of tomatoes, potatoes, and pepinos (Solanaceae). Am. J. Bot. 80:676-688.

Tai, T. H., Dahlbeck, D., Clark, E. T., Gajiwala, P., Pasion, R., Whalen, M. C., Stall, R. E., and Staskawicz, B. J. 1999. Expression of the Bs2 pepper gene confers resistance to bacterial spot disease in tomato. Proc. Natl. Acad. Sci. U.S.A. 96:14153-14158.
Tornero, P., Merritt, P., Sadanandom, A., Shirasu, K., Innes, R. W., and Dangl, J. L. 2002. RARl and NDR1 contribute quantitatively to disease resistance in Arabidopsis, and their relative contributions are dependent on the R gene assayed. Plant Cell 14:1005-1015.

van der Biezen, E. A., Freddie, C. T., Kahn, K., Parker, J. E., and Jones, J. D. G. 2002. Arabidopsis RPP4 is a member of the RPP5 multigene family of TIR-NB-LRR genes and confers downy mildew resistance through multiple signaling components. Plant J. 29:439-451.

van der Vossen, E., Sikkema, A., Hekkert, B., Gros, J., Stevens, P. Muskens, M., Wouters, D., Pereira, A., Stiekema, W., and Allefs, S. 2003. An ancient R gene from the wild potato species Solanum bulbocastanum confers broad-spectrum resistance to Phytophthora infestans in cultivated potato and tomato. Plant J. 36:867-882.

Walgenbach, J. 1997. Effect of potato aphid (Homoptera: Aphididae) on yield, quality, and economics of staked-tomato production. J. Econ Entomol. 90:996-1004.

Whitham, S., McCormick, S., and Baker, B. 1996. The $N$ gene of tobacco confers resistance to tobacco mosaic virus in transgenic tomato. Proc. Natl. Acad. Sci. U.S.A. 93:8776-8781.

Williamson, V. M., and Gleason, C. 2003. Plant-nematode interactions. Curr. Opin. Plant Biol. 6:327-333.

Xiao, S., Charoenwattana, P., Holcombe, L., and Turner, J. 2003. The Arabidopsis genes $R P W 8.1$ and $R P W 8.2$ confer induced resistance to powdery mildew diseases in tobacco. Mol. Plant-Microbe Interact. 16:289-294.

Yaghoobi, J., Kaloshian, I., Wen, Y., and Williamson, V. 1995. Mapping a new nematode resistance locus in Lycopersicon peruvianum. Theor Appl. Genet. 91:457-464. 